\title{
CASH OR CARD? A SHORT INSIGHT ON THE CHANGES CAUSED BY COVID-19 PANDEMIC
} https://doi.org/10.47743/jopafl-2021-20-09

\author{
Maria BARABAS \\ Drăgan European University Lugoj, \\ Lugoj, România \\ maria.barabas@deu.ro \\ Timeea-Maria SCHMIDT \\ Drăgan European University Lugoj, \\ Lugoj, România \\ dumescu_timeea_maria@yahoo.com
}

\begin{abstract}
The world changed and, together with it, all its constitutive systems. Either it is about the economic system or the social one, the recent events showed that change is possible, and even very rapidly. COVID19 pandemic substantially changed the way the people trade. The somewhat forced digitalization of all sectors brought with itself a "revolution" of the traditional thinking, a road of no return, a one-way road. Even without a solid infrastructure, the people demonstrated how quickly they could adapt themselves. Because the people who "tasted" the comfort of digitalisation will no longer want to go back to the previous comfort zone. In the financial and banking system, the card is not something new, but its use has known, during this period, an expansion without precedent. Similarly, the online transfer of money, through the applications offered by the banks.
\end{abstract}

Keywords: pandemic, payment system, bank card, digitalization

\section{Introduction}

The economic and social environment of the year 2020 reached a turning point at international level, caused by the sanitary crisis which destabilized the economic situation. The world was caught by surprise by the severe shock, and the reactions came very soon. Nevertheless, the situations was successfully exceeded in most of the sectors; there are losses, by the positive news regarding the covid-19 vaccine and, then, its production, together with a firm answer from the monetary and fiscal policies, brought their contribution to stabilizing the economic activity. But, as Mircea Coșea stated, the changes caused by the pandemic represent long-term tendencies of a new paradigm of functioning. In Romania, in March 2020, a national quarantine was established, which severely affected especially some sectors of activity, like, for example, tourism and HoReCa industry. The economic impact of the pandemic varies from one industrial sector to the other, all the sectors being affected in a certain measure.

It is interesting to notice the fact that, following the taken measures, the transactions with Visa cards in restaurants increased with 524\%, in food stores with $147 \%$ and in pharmacies with 64\%. Also, another consequence is the increase with $51 \%$ of card payments, compared to March 2019 (www.ceccarbusinessmagazine).

Regarding the number of card transactions and average value of each payment, there are significant differencies between the countries of the European Union - according 
to statistical data. Although the number of cards increased from March 2018 to December 2020 with more than 2 million cards, the reality is that Romania has less than one bank card per capita, this being one of the lowest values in the European Union member states, as a consequence of the predilection to pay cash

\section{Evolution of card portfolio in Romania}

The evolution of card portfolio in Romania has an increasing tendency beginning with 2015. Our supposition, based on statistical data, shows the fact that the transition to non-cash would have taken place anyway, but in a much slower rhythm. It would have taken place in time, together with the new generations, with those who appreciate the comfort offered by "a click" and feel safe when they use it. Thus, the COVID-19 pandemic made us accelerate the change.

As it follows, it is presented the way the card portfolio evolved in Romania:

Figure 1. Evolution of card portfolio in Romania

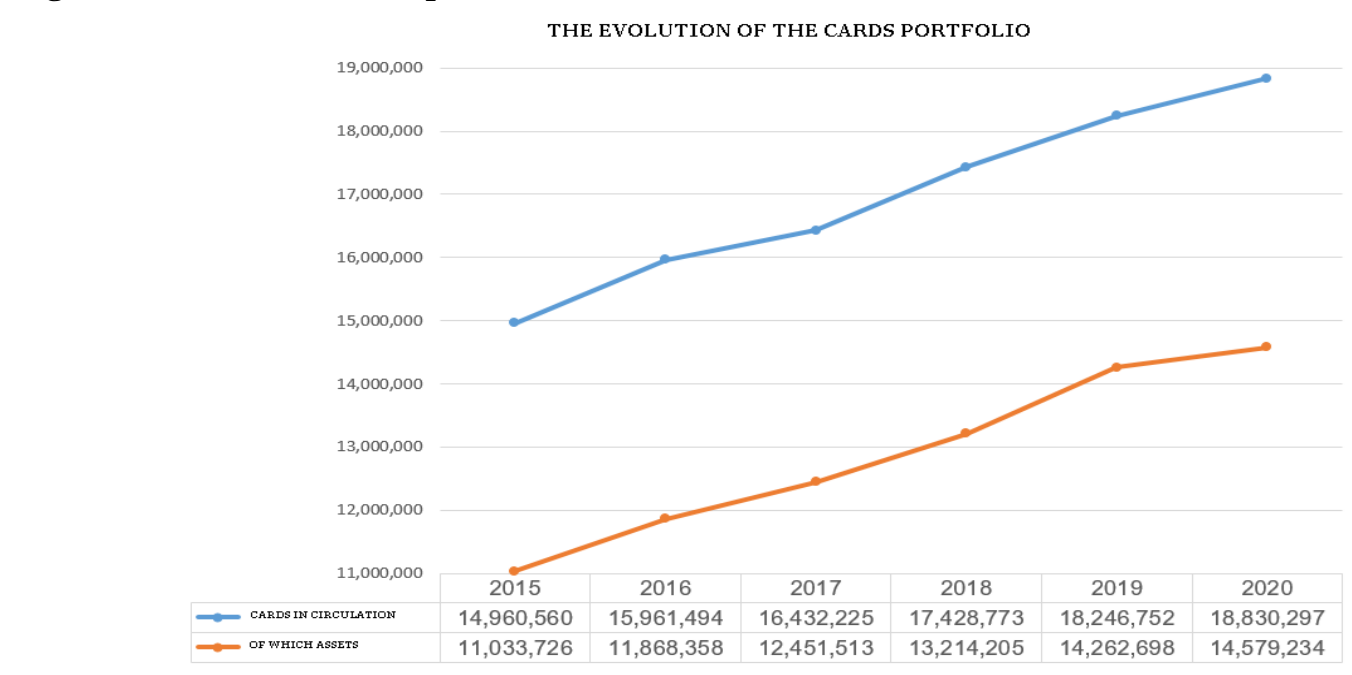

Source: BNR

In 2020, Romania closed the year 2020 with about 19 million valid cards in circulation, registering an increase of 580,000 units compared to the month of December of the previous year. The annual rhythm of growth of card portfolio in 2020 was of 3.2\% compared to 2019, a slow rhythm, but anyway, higher than the one registered in 2017, when it was registered an increase of only 470,000 units compared to 2016, thus a rhythm of growth of $+2.9 \%$. One of the strange situations on card market is represented by their activation degree. From some reasons, which do not make the object of study of this article, there is a large number of cards which were issued, but they are not used (one out of five cards is not activated), reaching in 2020 a record level of 4.25 million of unused units (22.6\%). In 2020, the number of inactive card increased with 316,000 units compared to the previous year, though a reduced increase, compared to the year 2019. It is important to mention the fact that the increase of card portfolio in 2020, in Romania, is due exclusively to debit cards (graph 2). 
Figure 2. Evolution of debit cards, respectively credit cards in Romania

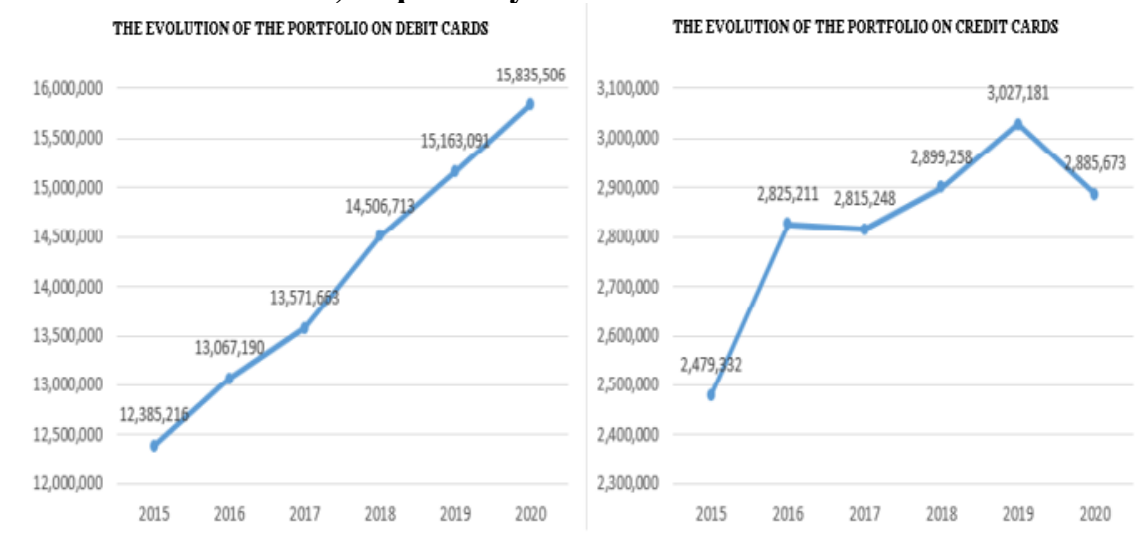

Source: BNR

The future of payments belongs to the digital solutions. Nowadays, we enjoy the benefits of technology, we can no longer imagine our life without a digital relation, its influence can be noticed in all sectors of activity. The representative of Mastercard in Romania and Croatia stated, in an interview, that the future belongs to digital solutions, to which the entire banking system will adapt to. The material the cards are made of, that is plastic, will disappear, step by step, from our wallets and will be replaced by Digital First Card, a service launched for the moment only in the United States, but it will get soon in Europe too.

\section{Methodology}

As method of research we used the focus group, that is an interview of a group of 8 persons, focused on the theme of changes regarding the payments caused by the pandemic According to Richard Krueger's opinion, we carefully prepared the interview, so that the information we get reveal what we planned to show. We took into account the fact that the response time varies depending the theme and the characteristics of the group, it being smaller than in the case of individual interviews because the groups of discussion do not last too much time. When choosing the method we took into consideration its advantages, firstly, the fact that the speakers stimulate each other in taking part to the discussion, and secondly, the experiences, ideas, opinions are simultaneously collected. Also, the participants were chosen on some homogeneous criteria, all holding a bachelor degree in finance and banking, working in the sector they were trained for. All the participants were aware of the fact that they were present to take part to a research and they would be present for about 1-2 hours. Also, in order to make the participants get familiar to one another, the session was preceded by a pre-session of about 10 minutes. They were all informed they would be registered, but, for their safety feeling, the registrations would be deleted 24 hours later, time necessary to register their answers.

The discussion focused on the main theme: the COVID-19 pandemic did change or did not change the habits of Romanian consumers regarding the way the payments are made and on some particular aspects:

- $\quad$ the use of cards makes us spend more compared to using cash;

- $\quad$ for how long most of Romanian have hold a card; 
- on what goal Romanian consumers use most their card;

- how often Romanian consumers use the card;

- $\quad$ to what extent is considered to be accessible the card payment;

- $\quad$ which are the main difficulties encountered when using the card.

After presenting the general theme, we invited the participants to express their opinions. As an observation, because at the beginning no one wanted to start the discussion, we invited one of the subjects to be the first who answers.

Following the discussions, we resumed the following:

- $\quad 5$ of the focus specialists consider that the use of card influences us to spend more than in the case of using cash, explaining that, from their own experience, but also from what other people said, there have no qualms of conscience when they spend large sum of money from the card, they not being used to consider the card as a banknote. Nevertheless, it was showed that the banking applications which send a sms after each transaction, have the role of making us aware of the payments just like when we pay cash, fact which makes us more and more make no difference between cash and card;

Figure 3. The use of card makes us spend more than in the case of using cash

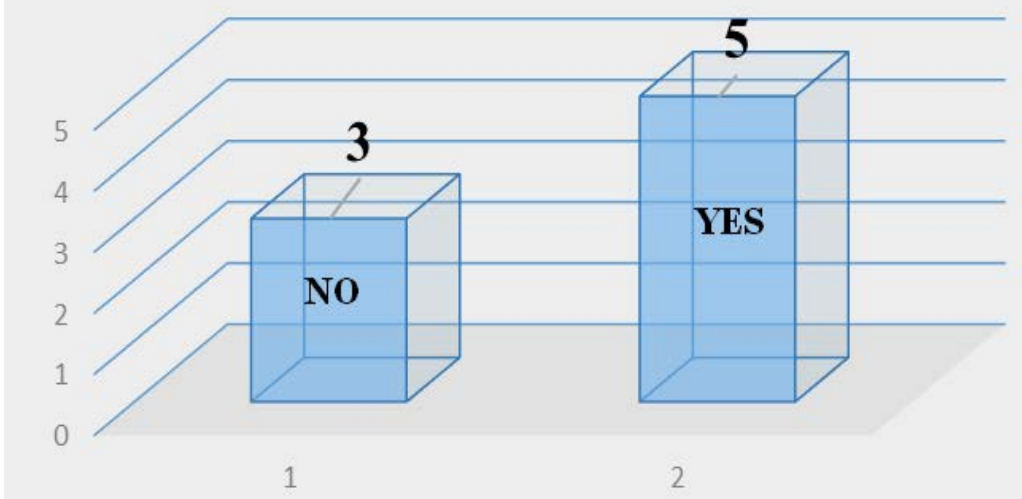

Source: Own processing

- the participants to the focus group stated that, according to the data they held, only about half of the Romanian citizens have held a card for more than 5 years, thus noticing more requests in the period 2020-2021 compared to other years;

- regarding the most frequent use of the card, 6 out of 8 participants to the focus group stated that, at least during the last year, from the data they held, most of the people used the card for shopping. On the second place would be the use of debit card for receiving the wage. Also, during the last year - the participants stated - the number of card payments for utilities invoices increased.

Figure 4. The most frequent use of bank card in Romania 


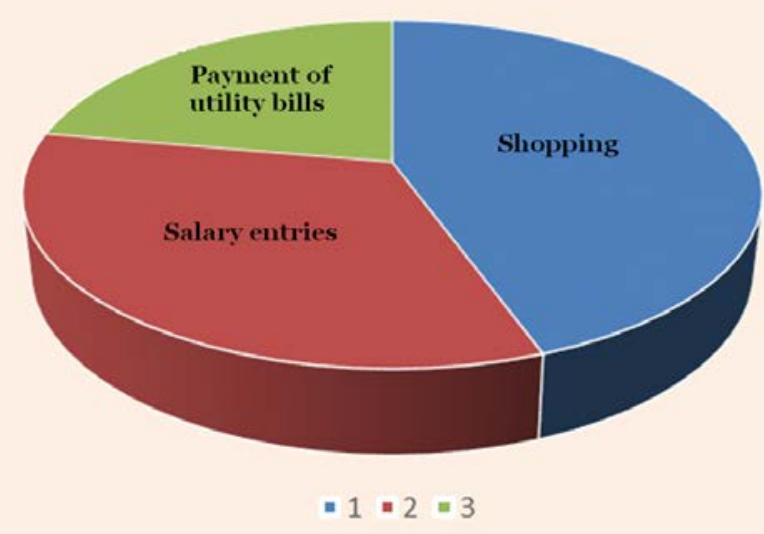

Source: Own processing

The participants concluded that the difficulties encountered when using the bank card are the following:

- the ATM ran out of money;

- $\quad$ the ATM did not work;

- $\quad$ some ATMs do not have the appropriate light and the display can be hardly seen;

- $\quad$ the card may get blocked in the ATM.

As a consequence, the difficulties related to the card are rather related to the ATM functioning.

\section{Conclusions}

The COVID-19 pandemic caused important changes in various aspects: one of them is the change of the way the payment is made when selling and buying. Some researchers consider that the old models got a break from which, when they would go out, they would remain unchanged. We consider that the change is irreversible. The use of cash as payment method is more and more replaced by the card and the online transfer of money. The people reoriented themselves to payments methods and means considered safer and more effective, when one of the measures taken during the pandemic was to self-isolate. Cash or card, in 2021? We incline to say card, as a variant for the payments. The lesson the pandemic taught us all is that by uniting our efforts, the world survives, adapts itself, and becomes an intelligent "system". Nowadays, the change ratio is increasing, the education is no longer linear and demands the help of digitalization, the tendencies are to dematerialize, it is needed to reorient on all plans: professional, social, day to day life.

\section{Reference}

1. Cechin Crista Persida (2013). Operations of credit institutions - 2nd revised edition, Solness Publishing House, Timişoara.

2. Lupu, D., Maha, L. G., \& Viorică, E. D. (2020). COVID-19 Incidence in Europe: Drivers and Government Interventions. Transylvanian Review of Administrative Sciences, 16(SI), 80-93. DOI: http://dx.doi.org/10.24193/tras.SI2020.5 
3. Coșea, M., (2021). There is also an economy in the pandemic. Studies and analyzes, Romania of Tomorrow Foundation Publishing House, Bucharest.

4. www.bnr.ro

5. www.ceccarbusinessmagazine.ro

6. World Health Organization. Novel Coronavirus (2019-nCoV) Situation. Report - 10. 2020. Available online: https://www.who.int/docs/default-source/coronaviruse/situation-reports/20200130-sitrep10-ncov .pdf? Sfvrsn = d0b2e480_2.2020 (accessed on 10 June 2021) Creative Commons Attribution - Non Commercial - No Derivatives 4.0 International License. 